\title{
Mystery of ice multiplication in warm-based precipitating shallow cumulus clouds
}

\author{
Jiming Sun, ${ }^{1,2}$ Parisa A. Ariya, ${ }^{1,3}$ Henry G. Leighton, ${ }^{1}$ and M. K. Yau ${ }^{1}$ \\ Received 11 January 2010; revised 6 April 2010; accepted 16 April 2010; published 21 May 2010.
}

[1] High concentrations of ice crystals exceeding those of background ice nuclei have often been observed in warmbased precipitating shallow cumulus clouds. Laboratory experiments reveal that such ice multiplication can occur when large ice particles collide with cloud droplets (Hallett-Mossop mechanism). Further studies suggested that this mechanism is unable to account for the exceedingly high ice concentrations in those kinds of clouds. However, the results of our numerical simulations show that the ice multiplication phenomena can be explained by the Hallett-Mossop mechanism with the freezing of a narrow band of supercooled raindrops which act as rimers playing a crucial role. Citation: Sun, J., P. A. Ariya, H. G. Leighton, and M. K. Yau (2010), Mystery of ice multiplication in warm-based precipitating shallow cumulus clouds, Geophys. Res. Lett., 37, L10802, doi:10.1029/2010GL042440.

\section{Introduction}

[2] One of the important unsolved problems in cloud microphysics is the rapid formation of exceptionally high ice particle concentrations in warm-based precipitating shallow cumulus clouds (WPSCCs) [Blyth and Latham, 1993; Hobbs and Rangno, 1998]. Ice particle concentrations can increase from less than $0.01 \mathrm{~L}^{-1}$ to more than $100 \mathrm{~L}^{-1}$ within 10 minutes in clouds with cloud top temperatures warmer than $-10^{\circ} \mathrm{C}$ [Hobbs and Rangno, 1990]. There are some theories explaining the production of high concentrations of ice particles in cumulus clouds. The most widely accepted mechanism responsible for the occurrence of ice particle concentrations in excess of those of ice nucleus measurements involves the production of numerous ice splinters during riming [Hallett and Mossop, 1974]. Laboratory experiments reveal that ice multiplication occurs when cloud droplets collide with ice [Hallett and Mossop, 1974; Mossop and Hallett, 1974]. The well-known HallettMossop (H-M) mechanism requires: (1) cloud temperatures between -3 and $-8^{\circ} \mathrm{C}$; (2) large cloud droplets (diameters greater than $24 \mu \mathrm{m}$ ) in concentrations of more than a few drops per $\mathrm{cm}^{3}$; (3) the ratio of the concentrations of droplets with diameters less than $13 \mu \mathrm{m}$ to those with diameters greater than $24 \mu \mathrm{m}$ to be greater than 0.1 [Mossop, 1985]. Although the $\mathrm{H}-\mathrm{M}$ mechanism has been known for several

\footnotetext{
${ }^{1}$ Department of Atmospheric and Oceanic Sciences, McGill University, Montreal, Quebec, Canada.

${ }^{2}$ Now at Department of Meteorology, University of Hawai'i, Honolulu, Hawaii, USA Canada.

${ }^{3}$ Department of Chemistry, McGill University, Montreal, Quebec,
}

Copyright 2010 by the American Geophysical Union. 0094-8276/10/2010GL042440 decades and can explain ice multiplication processes in some cumulus clouds, the formation of ice bursts in WPSCCs is still a mystery [Hobbs and Rangno, 1998].

[3] The H-M mechanism is always postulated to operate in cumulus clouds as follows [Hobbs and Rangno, 1998]. Graupel move through the temperature zone between -3 and $-8^{\circ} \mathrm{C}$ and intercept both cloud droplets greater than $24 \mu \mathrm{m}$ and less than $13 \mu \mathrm{m}$ diameter. During the riming process ice splinters are ejected. The ice splinters grow through water vapor deposition over a period of a few minutes to sizes where they can rime and produce more ice splinters while still in the $\mathrm{H}-\mathrm{M}$ temperature zone. This process continues until conditions are inappropriate for ice-splinter production. However, simulations that have included the H-M process in WPSCCs and that used predefined dynamic and thermodynamic fields have not been able to account for the observed characteristics (timing and concentration) of secondary ice particles.

[4] The main argument against the H-M mechanism is the rapid formation of ice crystal bursts. Previous studies suggest that to produce such significant ice particle concentrations through this mechanism requires a minimum of 25 minutes [Beheng, 1987; Mason, 1996].

[5] We argue that the previous studies may not have adequately taken into account the dynamics and thermal structures of cumulus clouds, or the evolution of water droplets in them. The theories to describe the ice initiation and ice multiplication should include both ice nucleation mechanisms and convective cloud dynamics because both of which are related to a factor that influences ice formation, namely the spectra of cloud droplets. The previous studies were based on too many assumptions concerning the evolution of water droplets, such as the constant vertical profile of the updraught velocities, the constant sizes of cloud droplets as well as the unrealistic assumption of constant total water contents (liquid and ice) in the rain drop formation and evolution processes [Beheng, 1987], or graupels were considered as the sole rimers and the role of raindrops in the rimer formation was ignored [Mason, 1996]. Consequently, in those studies the riming process was largely inhibited due to the lack of cloud droplets [Beheng, 1987] or ice splinter production was underestimated due to the long time needed for graupel formation [Mason, 1996].

[6] The salient features of observations in both maritime and continental WPSCCs [Rangno and Hobbs, 1991; Blyth and Latham, 1993; Rangno and Hobbs, 2005; Cantrell and Heymsfield, 2005] may be summarized as follows: (1) The highest ice particle concentrations generally appeared within 10 minutes and the entire cloud turret head glaciated spontaneously when the cloud top resided at or near its maximum level for more than a few minutes, but ice particles were absent from newly rising cloud towers. (2) The high 

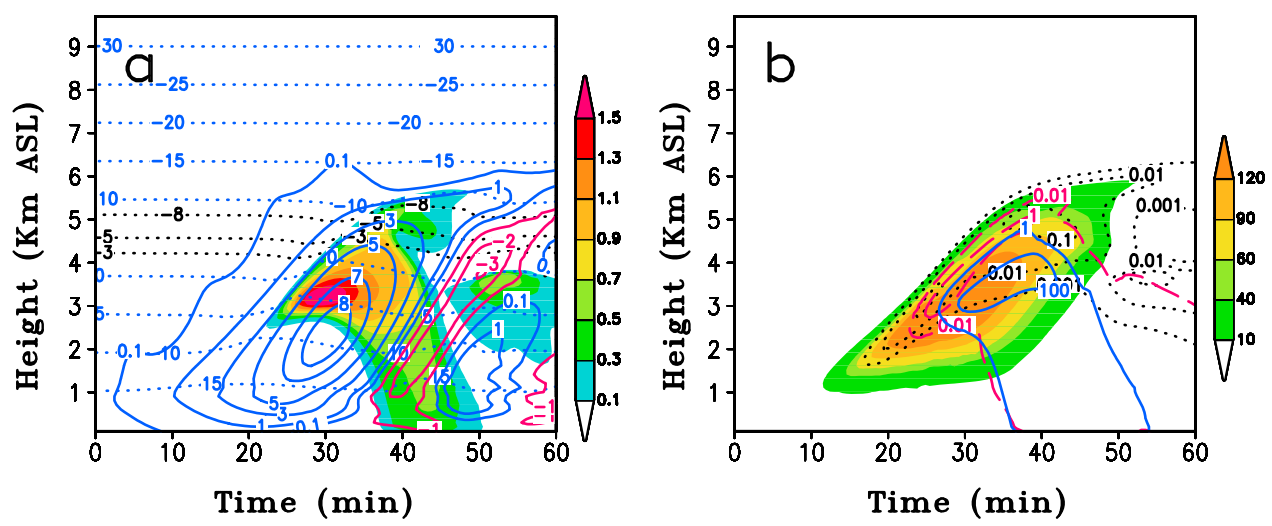

Figure 1. Spatial and temporal evolution of thermodynamic field and cloud droplet spectra. (a) Temperature $\left({ }^{\circ} \mathrm{C}\right)($ dotted lines), vertical velocity $\left(\mathrm{m} \mathrm{s}^{-1}\right.$ ) (solid lines) and rain water content (diameter $>100 \mu \mathrm{m}$ ) (in $\mathrm{g} \mathrm{m}^{-3}$ shaded area). (b) Cloud drops with diameters $>24.0 \mu \mathrm{m}\left(\mathrm{cm}^{-3}\right)$ (shaded area), drizzle drops with diameters $>100 \mu \mathrm{m}\left(\mathrm{cm}^{-3}\right)$ (dotted lines), small raindrops with diameters $>600 \mu \mathrm{m}\left(\mathrm{L}^{-1}\right)$ (dashed lines) and rain drops with diameters $>2 \mathrm{~mm}\left(\mathrm{~m}^{-3}\right)$ (solid lines).

concentrations of ice particles occurred almost simultaneously with the appearance of frozen drizzle drops (100 to $500 \mu \mathrm{m}$ diameter) and small raindrops (500 to $2000 \mu \mathrm{m}$ diameter). (3) The occurrence of high ice particle concentrations was strongly correlated with the breadth of the cloud droplet spectra near the cloud top with large cloud droplets $(25 \mu \mathrm{m}$ diameter) present in concentrations of a few per $\mathrm{cm}^{3}$. (4) Near the cloud top, water drops with diameters greater than $0.1 \mathrm{~mm}$ were observed in concentrations of more than $100 \mathrm{~L}^{-1}$ for typical cases before the ice bursts formed, and precipitation was present when the ice crystal concentration in the ice bursts was exceptionally high. (5) Cloud depth appeared to be a more important determinant of ice-crystal development than cloud-top temperature [Rangno and Hobbs, 1991; Blyth and Latham, 1993; Rangno and Hobbs, 2005]. (6) Ice particle size distributions indicate that small particles are continually being created. (7) The observed habits of ice crystals were not always consistent with the temperature range in which the HallettMossop mechanism operates. These complicated conditions for ice multiplication processes suggest that cloud dynamics and thermodynamics as well as the evolution of water droplets play important roles.

[7] Recent observational studies and modelling simulations [Ovtchinnikov et al., 2000; Rangno and Hobbs, 2005] showed that raindrop freezing can accelerate ice formation. The positive feedback between raindrops and ice splinters is responsible for the ice burst in multi-thermal cumulus clouds [Phillips et al., 2001]. Therefore, understanding the temporal and spatial evolution of raindrop spectra in WPSCCs is necessary to find out whether or not the H-M mechanism can account for the ice burst in WPSCCs.

\section{Cloud Modelling Study}

[8] Cloud modelling studies allow the ice initiation mechanisms and the H-M mechanism to be placed in a dynamic and thermodynamic framework and hence provide further insight into their roles in the ice multiplication process. Moreover, an evaluation of the part played by raindrops in the ice multiplication process is needed to answer whether or not the H-M mechanism can explain the ice burst phenomenon. We used a one-and-half dimensional model
(J. Sun et al., Modelling study of ice formation in warmbased precipitating shallow cumulus clouds: I. A new perspective on droplet spectral broadening, submitted to Journal of the Atmospheric Sciences, 2009a) for this study. The finding of Sun et al. (submitted manuscript, 2009a) that there is a continuous supply of relatively small cloud droplets at the cloud top in the developing stage of cumulus clouds challenges the hypothesis that the riming process will be inhibited due to the decrease of the cloud droplet concentration after rain formation [Beheng, 1987].

[9] Laboratory experiments have documented the dependence of secondary ice production rates by the H-M mechanism on temperature, the water drop spectrum and riming rate [Mossop, 1976, 1978]. Based on the measured secondary ice production rates [Mossop, 1978], we applied a parameterization which takes account of the drop spectra, collection efficiency for rimer-droplet collisions, and temperature variation [Harris-Hobbs and Cooper, 1987]. We used a profile modified from the one used by Yau [1980] and a maritime aerosol distribution with triple the concentrations given by O'Dowd et al. [1997]. We start aerosol activation and condensation growth of water droplets by a sinusoidal perturbation of potential temperature below the cloud base. The ice nucleus concentration at temperatures above $-10^{\circ} \mathrm{C}$ was assumed to be $0.27 \mathrm{~L}^{-1}$ (Sun et al., submitted manuscript, 2009a). We assumed that ice-nucleating bacteria acting in the immersion freezing mode are responsible for ice crystal formation. Sensitivity tests on the concentrations of ice nuclei, cloud condensation nuclei, different ice nuclei and other freezing modes are given by J. Sun et al. (Modelling study of ice formation in precipitating shallow cumulus clouds: II. Bioaerosols-triggered ice initiation and ice multiplication, submitted to Journal of the Atmospheric Sciences, 2009b).

\section{Modelling Results}

[10] Results show that the precipitation in this simulation mainly develops through the warm rain process as may be seen in Figure 1a. The distribution of vertical velocity implies that there is horizontal detrainment in the upper part and horizontal entrainment in the lower part of the cloud. The time variation of the depth of the ice multiplication tem- 

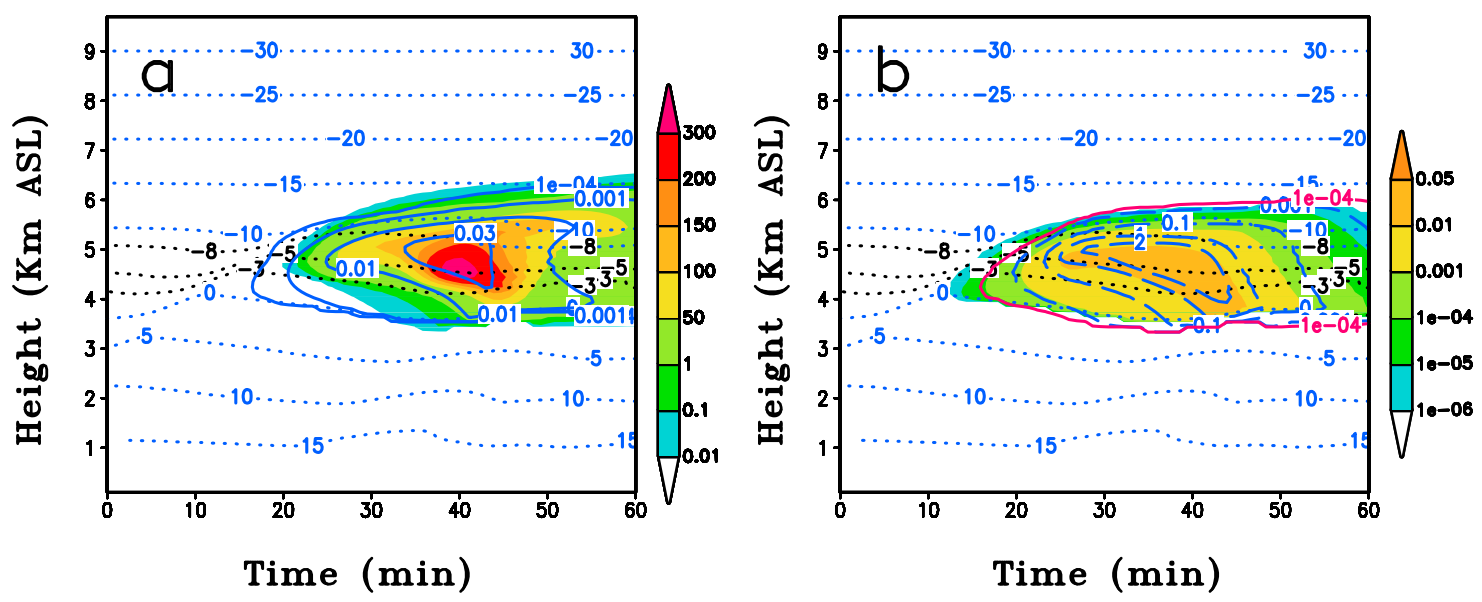

Figure 2. Spatial and temporal evolution of the ice particles. (a) Temperature $\left({ }^{\circ} \mathrm{C}\right)$ (dotted lines), ice crystal concentration $\left(\mathrm{L}^{-1}\right)$ (shaded area) and ice crystals containing IN $\left(\mathrm{L}^{-1}\right)$ (solid lines). (b) Temperature $\left({ }^{\circ} \mathrm{C}\right)$ (dotted lines), Concentration $\left(\mathrm{L}^{-1}\right)$ of ice pellets with diameter $>600 \mu \mathrm{m}$ that contain ice nuclei (shaded area), and concentration $\left(\mathrm{L}^{-1}\right)$ of ice pellets with diameter $>600 \mu \mathrm{m}$ (solid lines and dashed lines).

perature zone is mainly determined by the thermal processes of dry adiabatic cooling at the cloud top, condensational warming in the cloud, and evaporational cooling close to the base of the cloud. The cloud exhibits rapid ice production after about 40 minutes when the cloud top is near its maximum altitude (Figure 1a). The concentration of small ice particles increases from about $0.01 \mathrm{~L}^{-1}$ to $100 \mathrm{~L}^{-1}$ in less than 10 minutes (Figure 2a) much greater than the maximum concentration of ice particles containing bacteria (less than $0.05 \mathrm{~L}^{-1}$ ) at the cloud top in the dissipating stage. This value includes both primary ice crystals nucleated by bacteria and secondary crystals which scavenged bacteria. Clearly, the bacteria, although present in a relatively small concentration, trigger ice multiplication by being responsible for the formation of large ice particles. The concentration of primary ice pellets is far less than $0.05 \mathrm{~L}^{-1}$ (Figure 2b). The initiation time and concentration of primary ice pellets impact secondary ice pellet formation and subsequent ice bursts (Sun et al., submitted manuscript, 2009b). The appearance of the very high concentration of ice particles coincides with the occurrence of a high concentration of ice pellets and the disappearance of supercooled raindrops (Figure 3a). These modelling results are in agreement with previous field observations [Rangno and Hobbs, 1991; Blyth and Latham, 1993; Rangno and Hobbs, 2005].

[11] The mechanism responsible for the high ice crystal concentration is the positive feedback loop between ice splinter formation and the freezing of small raindrops. Raindrops with high concentrations fall into the ice multiplication temperature zone and encounter cloud-drops which have spectra consistent with the requirements of the H-M mechanism (Figures $3 \mathrm{a}$ and $3 \mathrm{~b}$ ). The raindrops collide with ice splinters, freeze, and then generate more splinters as they rime, thereby allowing the process to continue. The effectiveness of this feedback is highly dependent on the production rate of ice splinters through the H-M mechanism. The maximum average rate reaches 1.5 ice splinters per second per ice pellet in this simulation (Figure 3b). This rate is even less than that observed by Mossop [Mossop, 1978] who found values between 5 and 100 per second per ice
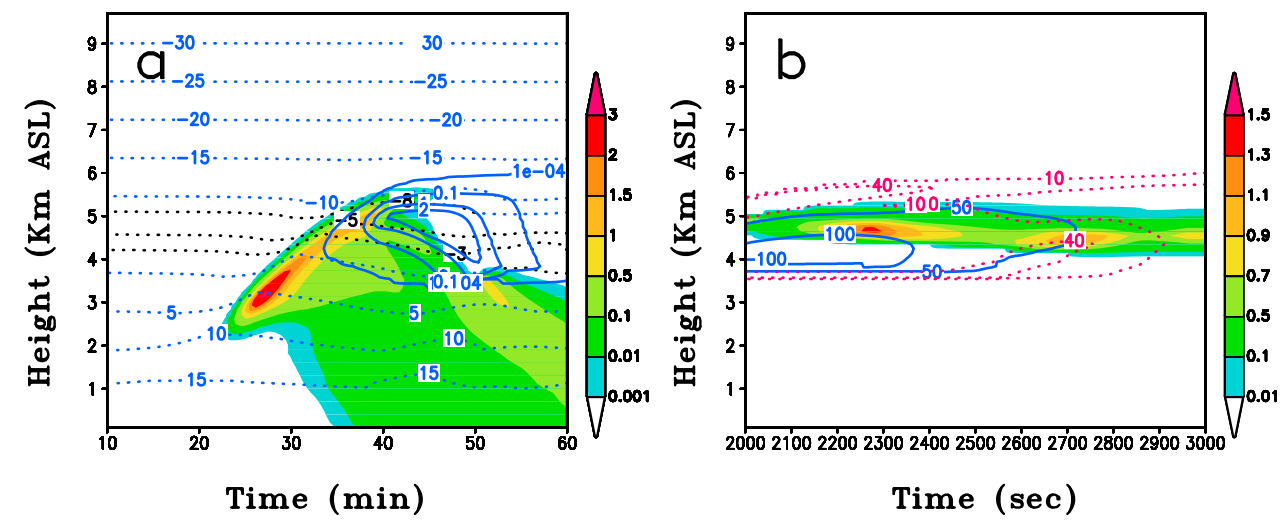

Figure 3. Spatial and temporal evolution of large hydrometeors and ice splinter production rates. (a) Temperature $\left({ }^{\circ} \mathrm{C}\right)$ (dotted lines), concentration $\left(\mathrm{L}^{-1}\right)$ of raindrops with diameter $>600 \mu \mathrm{m}$ (shaded area), and concentration $\left(\mathrm{L}^{-1}\right)$ of ice pellets with diameter $>600 \mu \mathrm{m}$ (solid lines). (b) Ice splinter production rate in the riming zone $\left(\mathrm{s}^{-1}\right.$ ice pellet $^{-1}$ ) (shaded area), concentrations $\left(\mathrm{cm}^{-3}\right)$ of small cloud drops $(5.0 \mu \mathrm{m}<$ diameter $<13 \mu \mathrm{m})$ (dotted lines) and large cloud drops (diameter $>24 \mu \mathrm{m}$ ) (solid lines). 

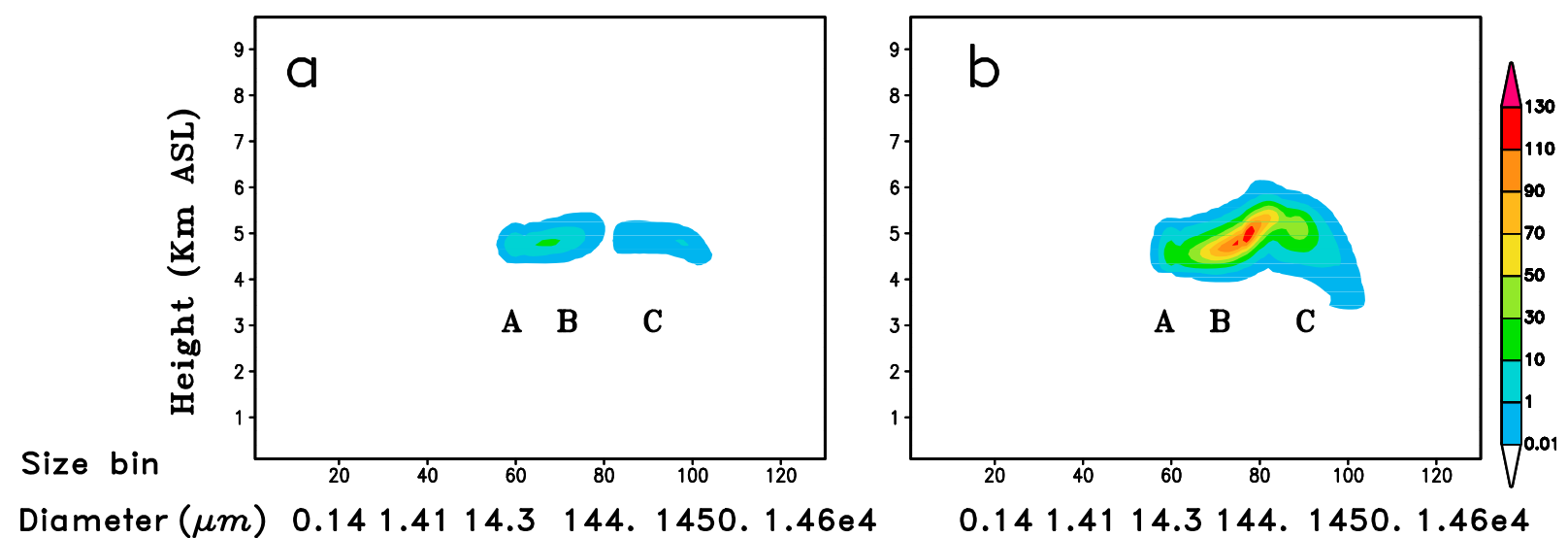

Diameter $(\mu m) \quad 0.141 .4114 .3144 .1450 .1 .46 e 4$

$0.141 .4114 .3144 .1450 .1 .46 e 4$

Figure 4. Ice particle spectra $\left(d N / d \log D \mathrm{~L}^{-1}\right)$ at time: (a) $38 \mathrm{~min}$, (b) $45 \mathrm{~min}$. Ice splinters (A), deposition-dominated particles (B) and ice pellets and riming-dominated particles (C).

pellet. The result that two high centers of production coincide with those of concentrations of large cloud drops and small clouddrops shows that ice splinter production rate is related to both small cloud drops and large drops. Figures $4 \mathrm{a}$ and $4 \mathrm{~b}$ show the size distributions of ice particles in these two high centers. The freezing of the raindrop band is responsible for the ice splinter formation. The concentration of ice splinters increases with the increase in concentration of ice pellets when concentrations of large and small drops are sufficient.

\section{Discussion and Conclusions}

[12] We observed that in addition to the presence of nuclei capable of generating primary ice particles at warm temperatures, two factors are responsible for the efficient ice multiplication in this simulation: the presence of cloud droplets with the necessary sizes in the temperature region associated with the H-M mechanism and the formation of a precipitation band containing drizzle and small raindrops which fall into the H-M temperature zone. At cloud base, new small cloud droplets $(<13 \mu \mathrm{m})$ are formed through nucleation before the beginning of the downdraft, while a large proportion of small cloud drops appear at the dissipating stage of cloud development when the downdraft occurs ( 37 mins). The downdraft cuts off the supply of moist air near the ground and dynamic entrainment of dry air at the cloud base dilutes the cloud resulting in smaller cloud droplets (Figure 3b). Simultaneously, evaporational cooling decreases the height of the base of the $\mathrm{H}-\mathrm{M}$ temperature zone and increases the thickness of this zone. In the dissipating stage of this WPSCCs, the H-M temperature zone is favorably located for ice multiplication.

[13] The time and heights of the initiation of precipitationsized drops are critically dependent on the cloud-drop size spectrum which is highly related to the concentration and distribution of aerosols and the profiles of temperature and humidity (Sun et al., submitted manuscript, 2009a). Observations suggest that drizzle drops appear as a result of stochastic collision coalescence processes when the concentration of large cloud droplets reaches a threshold value [Rangno and Hobbs, 2005]. Our study shows that drizzle drop concentration exceed $1 \mathrm{~L}^{-1}$ when the concentration of drops with diameters $>24 \mu \mathrm{m}$ is greater than $60 \mathrm{~cm}^{-3}$
(Figure 1b). A band of small raindrops with a depth of a few hundred meters appears in a concentration greater than $1 \mathrm{~L}^{-1}$ (Figure 1b) which is above the center of raindrops (greater than $2000 \mu \mathrm{m}$ diameter). These features of the modelling results are in good agreement with many observations [Rangno and Hobbs, 1991; Blyth and Latham, 1993; Rangno and Hobbs, 2005]. Therefore, if the height of cloud top surpasses the $\mathrm{H}-\mathrm{M}$ temperature zone, the precipitation band may reach this zone (Figure 3a). This implies that the formation and trajectories of precipitation-sized drops with high concentrations are the key factors responsible for ice bursts. The related issues, such as cloud depth, cloud drop size spectrum, aerosol concentrations and distributions and ice nuclei all influence the timing and the magnitude of ice multiplication (Sun et al., submitted manuscript, 2009b).

[14] In conclusion, ice multiplication in WPSCCs can be explained by the Hallett-Mossop mechanism under consideration of their cloud droplet evolution in the simple cloud model. The concentrations and compositions of IN at temperatures above $-10^{\circ} \mathrm{C}$ can influence the total concentrations of ice particles. But these changes are only significant when concentrations of IN vary in orders of magnitude (Sun et al., submitted manuscript, 2009b). Although, there is no direct evidence for biogenic nuclei acting in the atmosphere above $-10^{\circ} \mathrm{C}$, however, there is a body of evidence pointing to the presence of bio-organic particles in precipitation and their high ice nucleating activities above $-10^{\circ} \mathrm{C}[$ Brent et al., 2010]. The results found here are not necessarily restricted to cumulus clouds. Similar rapid enhancement of ice particle concentrations may also occur in large-scale stratiform clouds in which supercooled raindrops form as a result of some small scale convection within them.

[15] Acknowledgments. We appreciate financial support from the Natural Science and Engineering Research Council of Canada (NSERC), C-MAM. We are grateful to Marie Monier for her suggestions.

\section{References}

Beheng, K. D. (1987), Microphysical properties of glaciating cumulus clouds: Comparison of measurements with a numerical simulation, Q. J. R. Meteorol. Soc., 113, 1377-1382.

Blyth, A. M., and J. Latham (1993), Development of ice and precipitation on New Mexican summer time cumulus clouds, Q. J. R. Meteorol. Soc, 123, 1185-1198. 
Brent, C. C., R. Cai, C. E. Morris, K. S. McCarter, C. M. Foreman, M. L. Skidmore, S. N. Montross, and D. C. Sands (2010), Geographic, seasonal, and precipitation chemistry influence on the aboundance and activity of biological ice nucleators in rain and snow, Proc. Natl. Acad. Sci. U. S. A., 105, 18,854-18,859.

Cantrell, W., and A. Heymsfield (2005), Production of ice in tropospheric clouds: A review, Bull. Am. Meteorol. Soc., 86, 795-807.

Hallett, J., and S. C. Mossop (1974), Production of secondary ice particles during the riming process, Nature, 249, 26-28.

Harris-Hobbs, R. L., and W. A. Cooper (1987), Field evidence supporting quantitative predictions of secondary ice production rates, J. Atmos. Sci., 44, 1071-1082.

Hobbs, P. V., and A. L. Rangno (1990), Rapid development of ice particle concentrations in small, polar maritime cumuliform clouds, J. Atmos. Sci., 47, 2710-2722.

Hobbs, P. V., and A. L. Rangno (1998), Reply to "Comments by Alan M. Blyth and John Latham on 'Cumulus glaciation papers by P. V. Hobbs and A. L. Rangno,"” O. J. R. Meteorol. Soc., 124, 1009-1011.

Mason, B. J. (1996), The rapid glaciation of slightly supercooled cumulus clouds, Q. J. R. Meteorol. Soc., 122, 357-365.

Mossop, S. C. (1976), Production of secondary ice particles during the growth of graupel by riming, Q. J. R. Meteorol. Soc., 102, 45-57.

Mossop, S. C. (1978), The influence of drop size distribution on the production of secondary ice particles during graupel growth, J. Atmos. Sci, 102, 45-57.

Mossop, S. C. (1985), Secondary ice particle production during rime growth: The effect of drop size distribution and rimer velocity, $Q$. J. $R$ Meteorol. Soc., 111, 1113-3324.
Mossop, S. C., and J. Hallett (1974), Ice crystal concentration in cumulus clouds: Influence of the drop spectrum, Science, 186, 632-634.

O’Dowd, C. D., M. H. Smith, I. E. Consterdine, and J. A. Lowe (1997), Marine aerosol, sea salt, and the marine sulphur cycle: A short review, Atmos. Environ., 37, 73-80.

Ovtchinnikov, Y. L. Kogan, and A. M. Blyth (2000), An investigation of ice production mechanisms in small cumuliform clouds using a 3D model with explicit microphysics. Part II: Case study of New Mexico cumulus clouds, J. Atmos. Sci, 57, 3004-3020.

Phillips, V. T. J., A. M. Blyth, P. R. A. Brown, T. W. Choularton, and J. Latham (2001), The glaciation of a cumulus cloud over New Mexico, Q. J. R. Meteorol. Soc., 127, 1513-1534.

Rangno, A. L., and P. V. Hobbs (1991), Ice particle concentrations and precipitation development in small polar maritime cumuliform clouds, Q. J. R. Meteorol. Soc., 117, 207-241.

Rangno, A. L., and P. V. Hobbs (2005), Microstructures and precipitation development in cumulus and small cumuloonimbus clouds over the warm pool of the tropical Pacific Ocean, Q. J. R. Meteorol. Soc., 131, 639-673.

Yau, M. K. (1980), A two-cylinder model of cumulus cells and its application in computing cumulus transports, J. Atmos. Sci, 37, 2470-2485.

P. Ariya, G. H. Leighton, J. Sun, and M. K. Yau, Department of Atmospheric and Oceanic Sciences, McGill University, 805 Sherbrooke St. W., Montreal, QC H3A 2K6, Canada. (jiming.sun@mail.mcgill.ca; parisa.ariya@mcgill.ca) 